\title{
Studies on the Evaluation of the Half-sib Progenies to Identify the Prepotency of the Mother Clones of Hevea brasiliensis in Meghalaya
}

\author{
U. Chandra ${ }^{1 *}$, M. J. Reju' ${ }^{2}$, R. P. Singh ${ }^{1}$, G. Das ${ }^{3}$, D. Panda ${ }^{4}$ and K. K. Mydin ${ }^{2}$ \\ ${ }^{1}$ Regional Research Station, Rubber Research Institute of India, Dakopgre, Tura, Meghalaya (794 001), India \\ ${ }^{2}$ Rubber Research Institutes of India, Kottayam, Kerala (686 009), India \\ ${ }^{3}$ Rubber Research Institute of India, Regional Research Station, Guwahati, Assam (781 001), India \\ ${ }^{4}$ Dept. of Botany,Central University of Odisha, Koraput, Odisha (764 021), India
}

\section{Article History}

Manuscript No. AR1616

Received in $15^{\text {th }}$ June, 2016

Received in revised form $25^{\text {th }}$ September, 2016

Accepted in final form $7^{\text {th }}$ October, 2016

Correspondence to

"E-mail: umesh@rubberboard.org.in

\section{Keywords}

Half-sib progenies, girth, yield, prepotency, mother Hevea clones

\begin{abstract}
Two field experiments were conducted at Ganolgre Farm in the year 2008 and 2009, respectively under the Rubber Research Institute of India, Regional Research Station, Tura, West Garo Hills, Meghalaya (India) to identify the prepotent mother clones suitable for future breeding programmes in this region. Fully matured seeds were collected directly from the trees of the individual clones of Hevea and put on the germination bed. The germinated seeds were planted in two fields 10 days after collection. Growth observations viz. plant height, plant girth, number of whorls and the number of leaves were recorded annually before the start of the test tapping. After that all the seedlings were subjected to 10 test tapping. In 2008-trial the selected plants showed mean test tap yield range from 3.3-6.06 $\mathrm{g} \mathrm{t}^{-1} 10 \mathrm{t}^{-1}$ in which the maximum yield was recorded in the clone PB 5/51 (6.06 $\left.\mathrm{g} \mathrm{t}^{-1} 10 \mathrm{t}^{-1}\right)$ and minimum was in RRIM $600\left(3.3 \mathrm{~g} \mathrm{t}^{-1} 10 \mathrm{t}^{-1}\right)$ whereas in 2009-trial the selected plants showed mean test tap yield range from 2.4-5.4 $\mathrm{g} \mathrm{t}^{-1} 10 \mathrm{t}^{-1}$. The maximum yield in 2009 trial was recorded in RRII $105\left(5.4 \mathrm{~g} \mathrm{t}^{-1} 10 \mathrm{t}^{-1}\right)$ and minimum was in GL $1\left(2.4 \mathrm{~g} \mathrm{t}^{-1} 10 \mathrm{t}^{-1}\right)$. On the basis of the test tap yield the top yielding seedlings were selected and the selected bud-woods are maintained in the field for further breeding evaluation programme.
\end{abstract}

\section{Introduction}

Meghalaya being one of the potential areas of rubber cultivation in North-East India offers promise of economic stability for the growers of this region by way of adopting rubber cultivation. Due to the area expansion under rubber in the state the dependency on the traditional clones has increased significantly but growers do not have so many options of choosing the potential clones suitable for the region. Therefore, it has now become important to identify pre-potent clones through breeding programmes viz. half-sib progeny evaluation trials, full-sib progeny evaluation trials, poly-cross progeny evaluation trials etc.

The rubber tree (Hevea brasiliensis Wiil. ex Adr. de Juss. MuellArg.) is preferentially a cross pollinated crop with a long generative and testing or breeding cycle. Usually, three selection stages are involved in the breeding work for Hevea and it takes around 25 to 30 years until the final choice of clones for large scale planting (Goncalves et al., 1988). Usually one generative cycle takes four to five years (excluding seven to
10 years of evaluation for parental performance) and about 20 to 30 years for one testing cycle from the time of cross pollination. Thus, one of the most desirable innovations in tree breeding is a technique for predicting the breeding value of material at the juvenile stage (Varghese, 1992). The breeding in Hevea brasiliensis is practised on generating plants with high yield potential, followed by other secondary traits that contribute to the desirable increase in yield potential (Goncalves et al., 2001). The length of the juvenile phase is considered as the main obstacle in the breeding work of Hevea because it makes the process time consuming and lengthy (Tan, 1987; Simmonds, 1989; Varghese and Mydin, 2000). In Ginkgo it was observed that early identification of parent trees with the superior combination capacity is justified before mass production (Ocokoljic et al., 2011). Efficient early selection techniques were applied on seedlings younger than two years old in Apple also (Larsen et al., 2006; Koc et al., 2009). Earliness in Apple was found to have relation with leaf length, seedling height, trunk diameter, leaf chlorophyll concentration and number of branches etc. (Kazlovskaya, 
2005). Studies on genetic variances in the juvenile plant stage can maximize genetic gains while shortening the breeding cycle (Adams et al., 2007). Several attempts were made with varying degrees of success to predict major economic characters such as yield and vigour of the crop (Moreti et al., 1994; Boock et al., 1995; Goncalves et al., 1996). The prepotent ability of Hevea clones for producing high quality seedlings could be determined by systematic and planned experiments like seedling progeny analysis (Mydin et al., 1990). Half-sib progeny analysis from selected clones has been successfully utilised for the identifications of superior genotypes as well as pre-potent parents for future breeding programmes in Hevea (Mydin et al., 1990; Antony et al., 2014). Selection based on the multi-effect index maximizes genetic progress (Resende and Bertolucci, 1995) and should be used more in rubber tree breeding programmes (Costa et al., 2000). Different parameters like juvenile rubber yield, girth, latex vessel rows etc. were used by different workers for selection of superior genotypes in rubber (Mydin et al., 1996; Sebastian et al., 2005; Chandrasekhar et al., 2008; Mydin, 2012).

However, the success of any breeding methods depends on the breeding value of the parent clones. Unlike traditional areas, Meghalaya is situated in the north-eastern part of the country which experiences severe cold coupled with the frost during winter seasons which are considered to be detrimental for the growth of the Hevea. So far no efforts has been made on identifying prepotent parent clones with good general combining ability in the breeding programmes of Hevea in this region and this is the first ever effort in this direction. This experiment was started with dual aims (a) to identify and select high yielding half-sibs with desirable secondary characteristics and (b) to study the prepotency of parent clones to produce superior progeny in the Garo Hills of Meghalaya.

\section{Materials and Methods}

The present investigations were started at the Ganolgre Research Farm under the Regional Research Station, Tura, West Garo Hills, Meghalaya (India) in the year 2008 and 2009 as two trials, respectively to find out the prepotent mother clones using the Hevea seeds from the clonal evaluation trial areas of 1986 and 1985, respectively. The rubber seeds were collected from five Hevea clones (RRIC 105, PB5/51, RRIM 600, RRII 203 and PB 86) in 2008 and from seven Hevea clones (RRII 203, RRII 105, RRIM 600, PB 86, GL 1, GT 1 and PB 260) in 2009, individually and put on the germination bed. The germinated seeds were planted in two fields separately. In 2008 trial, the field planting was finished in the month of June, 2008 whereas in 2009 trial, the field planting was done in the month of October, 2009 in a randomized block design. In both of the trials a spacing of $60 \times 60 \mathrm{~cm}^{2}$ was followed. All the parent clones were selected for these trials on the basis of their performances in the clonal trials of 1985 and 1986 at Ganolgre farm. RRIM 600 clone was used as base clone in both of the trials to compare the field performances of the other clones. In 2008 trial, the total plant population was 272 in which PB 86 had the maximum progeny population (156 plants) and the minimum was in RRII 203 (8 plants). The total progeny population was 330 in 2009 trial.

To identify the superior progenies plant girth and test tap yield data were considered as the main criteria for selection. The plant girth along with the other growth parameters viz. plant height, number of leaves, number of whorls of the individual seedlings was recorded one year after planting and before the test tapping in both of the trials at a height of 20 $\mathrm{cm}$ above the ground. After two years of the planting all the seedling plants were subjected to the 10 test tapping in both of the trials following the method of (Mydin et al., 2004) in order to select the potential seedling plants during early stage. During test tapping proportionate quantity of formic acid was used to coagulate the latex. After finishing the test tapping the cup lumps of the individual plants were collected in petridishes and put in the hot air oven for 2-3 days to dry. After completely dry clone-wise dry weight of the cup lumps from individual plants was recorded and analyzed. The mean girth and test tap yield of 2008 trial were $7.16 \mathrm{~cm}$ and $1.82 \mathrm{~g}$ $\mathrm{t}^{-1} 10 \mathrm{t}^{-1}$ respectively and that in trial 2009 it was $7.59 \mathrm{~cm}$ and $1.40 \mathrm{~g} \mathrm{t}^{-1} 10 \mathrm{t}^{-1}$. The seedlings having more than the average test tap yield were selected and from this selection top $20 \%$ populations on the basis of plant girth and test tap yield were selected for further evaluation.

\section{Results and Discussion}

The Ganolgre area falls under the West Garo Hills district on the western part of the state of Meghalaya. It is situated on the latitudes of $25^{\circ} 52^{\prime} \mathrm{N}$ and longitudes of $90^{\circ} 22^{\prime}$ E receiving an average annual rainfall of more than $2600 \mathrm{~mm}$ during the period of the experiment. The rainfall is well distributed in the region. The site of the trial is situated at an altitude of 349 $\mathrm{m}$ amsl. The temperature in the region ranges from $16.5^{\circ} \mathrm{C}$ to $29.4{ }^{\circ} \mathrm{C}$ with average bright sunshine hours of 5.1 hours. Data on the survival percentage at the time of test tapping was recorded and presented in the table. Progeny from RRIC 105 and RRII 203 had $100 \%$ survival of the plant populations whereas the progeny of PB 86 had $91 \%$ plant survival. Those of PB 5/51 and RRIM 600 showed the lowest survival (86\% each). The average plant survival was $92.6 \%$ in 2008 trial whereas in 2009 trial the total seedlings survival was $78.7 \%$ with highest survival in the progeny of RRII 203 followed by 
GT 1 and minimum survival was in progeny of PB 86 (Table 1). RRIM 600 which is a popular clone in the non-traditional rubber growing region had moderate performance in terms of the survival of its progeny in both of the trials. This report is in conformity with the Antony, P.D. et al., 2014.

The growth performance of progeny of RRIC 105 was

\begin{tabular}{|c|c|c|c|}
\hline \multicolumn{4}{|c|}{$\begin{array}{l}\text { Table 1: Survival percentage of the } 2008 \text { and } 2009 \text { Half-Sib } \\
\text { progenies at the time of test tapping (two years after planting) }\end{array}$} \\
\hline $\begin{array}{l}\text { Progeny/ } \\
\text { clone }\end{array}$ & $\begin{array}{l}\text { Original popula- } \\
\text { tion size at the } \\
\text { time of planting }\end{array}$ & $\begin{array}{l}\text { Population size } \\
\text { at the time of } \\
\text { test tapping }\end{array}$ & $\begin{array}{c}\text { Survival } \\
(\%)\end{array}$ \\
\hline \multicolumn{4}{|c|}{2008 progeny } \\
\hline RRIC 105 & 36 & 36 & 100 \\
\hline PB 5/51 & 36 & 31 & 86 \\
\hline $\begin{array}{l}\text { RRIM } \\
600\end{array}$ & 36 & 31 & 86 \\
\hline RRII 203 & 8 & 8 & 100 \\
\hline PB 86 & 156 & 142 & 91 \\
\hline Mean & 54.4 & 49.6 & 92.6 \\
\hline SD & 58.08 & 52.78 & 7.06 \\
\hline \multicolumn{4}{|c|}{2009 progeny } \\
\hline PB 86 & 99 & 71 & 71.1 \\
\hline GL 1 & 41 & 32 & 78 \\
\hline GT 1 & 46 & 38 & 82.6 \\
\hline RRII 203 & 62 & 57 & 91.9 \\
\hline $\begin{array}{l}\text { RRIM } \\
600\end{array}$ & 47 & 37 & 78.7 \\
\hline RRII 105 & 18 & 13 & 72.2 \\
\hline PB 260 & 17 & 13 & 76.5 \\
\hline Mean & 47.1 & 37.3 & 78.7 \\
\hline $\mathrm{SD}$ & 28.01 & 21.34 & 7.01 \\
\hline
\end{tabular}

superior compared to the others in terms of plant height, plant girth, number of leaves and test tap yield in 2008 trial whereas in 2009 trial progeny of RRII 203 had the highest plant height and girth but highest test tap yield was recorded in RRII 105 followed by RRIM 600 and lowest was in the progeny of PB 86 (Table 2). The superiority of progeny of RRII 105 was reported earlier too (Mydin et al., 1990; 1996). The present results indicated PB 86 to be an inferior parent clone since in both the 2008 and 2009 populations the performance of progeny of this clone was inferior. For selecting the prepotent mother clones of the half-sib progenies, the juvenile yield plays an important role since in most of the cases this factor has been used earlier also for selecting the best mother clones. The mean juvenile yield of $4.14 \mathrm{~g} \mathrm{t}^{-1} 10 \mathrm{t}^{-1}$ of 12 clones from two years old seedlings

\begin{tabular}{|c|c|c|c|c|c|}
\hline Clone (m) & $\begin{array}{l}\text { Plant } \\
\text { height }\end{array}$ & $\begin{array}{l}\text { Girth } \\
(\mathrm{cm})\end{array}$ & $\begin{array}{c}\text { Leaves } \\
\text { no. }\end{array}$ & \multicolumn{2}{|c|}{$\begin{array}{c}\text { Test tap yield } \\
\left(\mathrm{g} \mathrm{t}^{-1} 10 \mathrm{t}^{-1}\right)\end{array}$} \\
\hline \multicolumn{6}{|c|}{2008 progeny } \\
\hline RRIC 105 & 2.9 & 7.9 & 23.3 & \multicolumn{2}{|c|}{2.4} \\
\hline PB 5/51 & 12.5 & 7.1 & 19.7 & \multicolumn{2}{|c|}{1.8} \\
\hline RRIM 600 & 2.7 & 7.3 & 23.5 & \multicolumn{2}{|c|}{1.03} \\
\hline RRII 203 & 2.7 & 6.7 & 21.4 & \multicolumn{2}{|c|}{1.96} \\
\hline PB 86 & 2.4 & 6.8 & 17.8 & \multicolumn{2}{|c|}{1.91} \\
\hline $\operatorname{SEm} \pm$ & 1.36 & 0.13 & 0.20 & \multicolumn{2}{|c|}{0.10} \\
\hline $\begin{array}{l}\text { LSD }^{*} \\
(p<0.05)\end{array}$ & 3.81 & 0.36 & 0.55 & \multicolumn{2}{|c|}{0.28} \\
\hline \multicolumn{6}{|c|}{2009 progeny } \\
\hline Clone (m) & $\begin{array}{l}\text { Plant } \\
\text { height }\end{array}$ & $\begin{array}{l}\text { Girth } \\
(\mathrm{cm})\end{array}$ & $\begin{array}{c}\text { Leaves } \\
\text { no. }\end{array}$ & $\begin{array}{c}\text { Whorls } \\
\text { no. }\end{array}$ & $\begin{array}{l}\text { Test tap } \\
\text { yield }(\mathrm{g} \\
\left.\mathrm{t}^{-1} 10 \mathrm{t}^{-1}\right)\end{array}$ \\
\hline PB 86 & 2.46 & 7.3 & 18.4 & 4.4 & 1.10 \\
\hline GL 1 & 2.82 & 7.4 & 23.5 & 4.5 & 1.21 \\
\hline GT 1 & 2.83 & 7.9 & 22.7 & 4.7 & 1.23 \\
\hline RRII 203 & 3.25 & 8.4 & 18.8 & 4.9 & 1.33 \\
\hline RRIM 600 & 3.03 & 7.6 & 19.5 & 4.6 & 1.53 \\
\hline RRII 105 & 2.60 & 8.0 & 20.0 & 3.9 & 2.18 \\
\hline PB 260 & 2.2 & 6.5 & 15.6 & 3.8 & 1.19 \\
\hline $\mathrm{SEm} \pm$ & 0.06 & 0.13 & 0.53 & 0.06 & 0.06 \\
\hline $\begin{array}{l}\mathrm{LSD}^{*} \\
(p<0.05)\end{array}$ & 0.16 & 0.35 & 1.49 & 0.18 & 0.18 \\
\hline
\end{tabular}

was reported by Sebastian and Saraswathyamma, 2005 in Malaysia and Thailand, respectively. The performance of the clone RRII 105 was superior during 2008 and 2009 both and the seedlings of this clone had highest plant girth and test tap yield.

The data presented in different tables on the growth performance of the different half-sibs in 2008 and 2009 trials revealed that plant girth cannot be correlated with the juvenile yields. The plants having less girth at the time of test tapping produced more yield than the plants having more plant girths after two and half years of growth. The criteria used for the identification of the superior progeny families was the performance of the seedlings after two years of growth and the parameters for the selection were mainly the plant height (m), plant girth (cm) and test tap yield $\left(\mathrm{g} \mathrm{t}^{-1} 10 \mathrm{t}^{-1}\right)$. Around $20 \%$ populations were selected and maintained in the field for further evaluation in the clonal nursery programme.

The data on girth and test tap yield of $20 \%$ selected population showed that in 2008 trial as many as 27 number of plants 
could be selected as top ranker whereas, in 2009 trial it was only 6 number belonging to the clone PB 86 (Table 3). In general the number of plants in each progeny under top rank i.e. above average test tap yield was less in 2009 trial compared to 2008 trial. In 2008 trial none of the plants from progeny RRII 203 showed above average girth and yield and thus could not be selected under high category whereas, in 2009 trial it was 8 numbers. In 2008 trial, the progeny of PB $5 / 51$ showed as high as $6.1 \mathrm{~g} \mathrm{t}^{-1} 10 \mathrm{t}^{-1}$ yield while the lowest yield was recorded in RRIM 600. In 2009 trial the highest test tap yield was observed in RRII 105 and that in GT 1 and RRII 203 it was the lowest. The average girth and test tap yield in 2008 trial was higher than that of 2009 trial indicating that weather at the time of planting as well as during early establishment stage may influence growth and yields of plants and also progeny variance. Success of breeding programs depends on precise estimates of genetic parameters (Klapste et al., 2007) and thus evaluation of these selective prepotent ortets in large scale is needed for further screening under the agro-climate of Garo Hills of Meghalaya.

\begin{tabular}{|c|c|c|c|c|c|}
\hline $\begin{array}{l}\text { Parent } \\
\text { clone }\end{array}$ & NP & $\begin{array}{l}\text { PS } \\
(\%)\end{array}$ & $\begin{array}{l}\text { Mean } \\
\text { girth } \\
(\mathrm{cm})\end{array}$ & MTTY & $\begin{array}{l}\text { Range of test } \\
\text { tap yield } \\
\left(\mathrm{g} \mathrm{t}^{-1} 10 \mathrm{t}^{-1}\right)\end{array}$ \\
\hline \multicolumn{6}{|c|}{2008 progeny } \\
\hline RRIC 105 & 8 & 22.2 & 9.2 & 4.9 & $3.7-5.8$ \\
\hline PB 5/51 & 6 & 19.4 & 9.1 & 4.8 & $4.3-6.1$ \\
\hline RRIM 600 & 3 & 9.7 & 8.5 & 4.7 & $3.3-5.9$ \\
\hline \multicolumn{6}{|l|}{ PB 86} \\
\hline 27 & 19.0 & 8.8 & 4.0 & $3.4-5.5$ & \\
\hline \multicolumn{6}{|c|}{2009 progeny } \\
\hline PB 86 & 6 & 8.5 & 8.3 & 2.8 & $2.5-3.2$ \\
\hline GL1 & 2 & 6.3 & 8.5 & 2.6 & $2.4-2.8$ \\
\hline GT1 & 5 & 13.2 & 8.8 & 3.3 & $2.3-4.4$ \\
\hline RRII 203 & 8 & 14.0 & 10.0 & 2.8 & $2.3-3.4$ \\
\hline RRIM 600 & 4 & 10.8 & 7.8 & 3.3 & $2.7-4.3$ \\
\hline RRII 105 & 2 & 15.4 & 8.5 & 5.2 & $4.9-5.4$ \\
\hline PB 260 & 1 & 7.7 & 7.0 & 2.3 & - \\
\hline
\end{tabular}

NP: No. of plants in 20\% selections; PS: Proportion of selections; MTTY: Mean test tap yield $\left(\mathrm{g} \mathrm{t}^{-1} 10 \mathrm{t}^{-1}\right)$

\section{Conclusion}

A set of seedlings raised from half-sib progenies of different clones concluded that the analysis of morphological traits like girth and test tap yield at juvenile stage within this halfsib lines provided bases for selecting prepotent ortets having high potential for growth and yield attributes. Thus PB 5/51 was found to be a potent clone followed by RRIM 600 for studying breeding in open pollinated half-sib system. Further evaluation on half-sib progeny analysis would be worth investigating.

\section{Acknowledgement}

The author is grateful for the encouragement and facilities provided by Director (Research), RRII, Kottayam and are thankful to late Dr. A.P. Thapliyal, Dy. Director, RRS, Tura for the valuable help and guidance.

\section{References}

Adams, J.P., Rousseau, R.J., Adams, J.C., 2007. Genetic performance and maximizing genetic gain through direct and indirect selection in cherrybark oak. Silvae Genetica 56, 80-88.

Antony, P.D., Dey, S.K., Mydin, K.K., 2014. Identification of superior genotypes and prepotent parent clones of Hevea in North East India by half-sib progeny analysis. Rubber Science 27(2), 234-242.

Boock, M.V., Goncalves, P.S., Bortoletto, N., Martins, A.L.M., 1995. Heritability, genetic variability and genetic gains for production and morphological traits in young progenies of rubber. Brazilian Agricultural Research 30, 673-681.

Chandrasekhar, T.R., Gireesh, T., 2008. Latex as yield may be better than rubber yield in juvenile screening for selection in rubber (Hevea brasiliensis Muell. Arg.). Journal of Natural Rubber Research 11(1), 52-58.

Costa, R.B., Resende, M.D.V., Araujo, A.J., Goncalves, P.S., 2000. Selection and genetic gain in rubber tree (Hevea) populations using a mixed mating system. Genetics and Molecular Biology 23(3), 671-679.

Goncalves, P.S., Cardoso, M., Bortoletto, N., 1988. Reduction of the breeding cycle and selection in obtaining rubber tree cultivars (Hevea sp.). Agronomy 40, 112-130.

Goncalves, P.S., Martins, A.L., Bortoletto, N., Tanzini, M.R., 1996. Estimates of genetic parameters and correlations of juvenile characters based on open pollinated progenies of Hevea. Brazilian Journal of Genetics 19, 105-111.

Goncalves, P.S., Battaglia, O.C., Ortoloni, A.A., Fonseca, F.S., 2001. Hevea culture. Manual for the State of Sao Paulo, IAC, Campinas, (Technical Bulletin, 189), 78.

Kazlovskaya, Z., 2005, National workshop on fruit breeding. Horticulture department, Seed and Plant Improvement Institute, Karaj, Iran.

Koc, A., Akbulut, M., Orhan, E., Celik, Z., Bilgener, S., Ercisli, S., 2009. Identification of Turkish and standard apple root stock. Genetics and Molecular Research 8, $420-425$. 
Klapste, J., Lstiburek, M.J., Kobliha, M.J., 2007. Initial evaluation of half-sib progenies of Norway spruce using the best linear unbiased prediction. Journal of Forest Science 53(2), 41-46.

Larsen, A.S., Asmussen, C.B., Coart, E., Olrik, D.C., Kjaer, E.D., 2006. Hybridization and genetic variation in Danish populations of European crab apple (Malus sylvestris). Tree Genetics and Genomes 2, 86-97.

Moreti, D., Goncalves, P.S., Gorgulho, E.P., Martins, A.L.M., Bortoletto, N., 1994. Estimates of genetic parameters and expected gains with the selection of juvenile characters in rubber tree progenies. Brazilian Agricultural Research 29, 1099-1109.

Mydin, K.K., Nazeer, M.A., SaraswathyAmma, C.K., 1990. Heterosis for juvenile vigour in Hevea brasiliensis. Indian Journal of Natural Rubber Research 3(1), 69-72.

Mydin, K.K., Gopinathan Nair, V., Panikkar, A.O.N., Saraswathy, P., Sethuraj, M.R., 1990. Prepotency in rubber I. Early estimation through juvenile traits. In: Proceedings national symposium on new trends in crop improvement of perennial species, Rubber Research Institute of India (R.R.I.I.), Kottayam, 114-123.

Mydin, K.K., Gopinathan Nair, V., Sethuraj, M.R., Nazeer, M.A., Panikkar, A.O.N., 1996. Prepotency in rubber II. Seedling progeny analysis for yield and certain yield attributes. Indian Journal of Natural Rubber Research 9(1), 63-66.

Mydin, K.K., Licy, J., Varghese, Y.A., John, A., Nair, R.B., Saraswathyamma, C.K., 2004. Clonal nursery evaluation for shortening the breeding cycle in Hevea brasiliensis. Natural Rubber Research 17(1), 60-66.
Mydin, K.K., 2012. Juvenile-mature correlations and associations among rubber yield and yield attributes in Hevea brasiliensis. Natural Rubber Research 25(1), $1-12$.

Ocokoljic, M., Grbic, M., Anastasijevic, N., 2011. Characteristics and variability of Half-sib progeny as the base for ginkgo breeding. African Journal of Biotechnology 10(85), 19752-19757.

Resende, M.D.V., Bertolucci, F.L.G., 1995. Maximization of genetic gain with restriction on effective population size and inbreeding in Eucalyptus grandis. In: Proceedings of the CRCTHF-INFRO Conference, Hobart, 167-170.

Sebastian, T., Saraswathyamma, C.K., 2005. Seedling progeny analysis for estimation of prepotency in exotic Hevea clones. Indian Journal of Botanical Research 1(2), 279-287.

Simmonds, N.W., 1989. Rubber Breeding In: Webster, C.C., Baulkwill, W.J. (Eds.), Rubber. England: Longmann Scientific Technical, 85-124.

Tan, H.,1987. Strategies in rubber tree breeding. In: Abbott, J., Atkin, R.K. (Eds.). Improving Vegetative Propagated Crops. London Academic, 27-62.

Varghese, Y.A., John, A., Premakumari, D., Panikar, A.O.N., Sethuraj, M.R., 1992. Early evaluation in Hevea: Growth and yield at the juvenile phase. Indian Journal of Natural Rubber Research 6(1\&2), 19-23.

Varghese, Y.A., Mydin, K.K., 2000. Genetic Improvement, In: George, P.J., Jacob, C.K. (Eds.), Natural Rubber: Agro-management and Crop Processing. Rubber Research Institute of India, Kottayam, India, 297-308. 